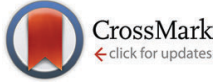

Cite this: J. Mater. Chem. C, 2016, 4, 1295

Received 2nd December 2015, Accepted 4th January 2016

DOI: $10.1039 / c 5 t c 04063 a$

www.rsc.org/MaterialsC

\title{
Multilayer $\mathrm{MoS}_{2}$ growth by metal and metal oxide sulfurization $\dagger$
}

\author{
M. H. Heyne, ${ }^{a b c}$ D. Chiappe, ${ }^{a b}$ J. Meersschaut, ${ }^{b}$ T. Nuytten, $^{b}$ T. Conard, $^{b}$

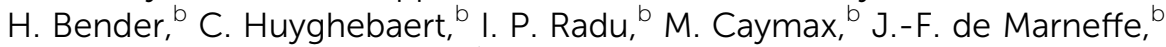 \\ E. C. Neyts ${ }^{c}$ and S. De Gendt ${ }^{a b}$
}

\begin{abstract}
We investigated the deposition of $\mathrm{MoS}_{2}$ multilayers on large area substrates. The pre-deposition of metal or metal oxide with subsequent sulfurization is a promising technique to achieve layered films. We distinguish a different reaction behavior in metal oxide and metallic films and investigate the effect of the temperature, the $\mathrm{H}_{2} \mathrm{~S} / \mathrm{H}_{2}$ gas mixture composition, and the role of the underlying substrate on the material quality. The results of the experiments suggest a $\mathrm{MoS}_{2}$ growth mechanism consisting of two subsequent process steps. At first, the reaction of the sulfur precursor with the metal or metal oxide occurs, requiring higher temperatures in the case of metallic film compared to metal oxide. At this stage, the basal planes assemble towards the diffusion direction of the reaction educts and products. After the sulfurization reaction, the material recrystallizes and the basal planes rearrange parallel to the substrate to minimize the surface energy. Therefore, substrates with low roughness show basal plane assembly parallel to the substrate. These results indicate that the substrate character has a significant impact on the assembly of low dimensional $\mathrm{MoS}_{2}$ films.
\end{abstract}

\section{Introduction}

Transition-metal dichalcogenides (TMD) such as $\mathrm{MoS}_{2}$ or $\mathrm{WS}_{2}$ are interesting materials for future transistor applications, but their large-area deposition is challenging. The first transistor devices based on TMDs were demonstrated on mechanically exfoliated flakes. ${ }^{1,2}$ The mechanical exfoliation allows only the deposition of sheets up to a few $\mu^{2}$ size, which makes this process inappropriate for high device densities on large areas. In addition, exfoliated flakes which are considered as best material quality at this juncture, show spatial variations in their properties. ${ }^{3-5}$ TMD films have been deposited by chemical vapor deposition ${ }^{6-8}$ on substrates up to a few $\mathrm{cm}^{2}$. This deposition can be achieved by the vaporization of solid $\mathrm{MoO}_{3}$ and $\mathrm{S}$ in a furnace under inert carrier gas flow. However, this technique is very sensitive to the amount of the precursor, the carrier gas flow in the furnace, and the substrate temperature itself, and therefore it is difficult to scale to larger substrate dimensions. To decrease the vaporization influence of the metal precursor, it is possible to pre-deposit a transition-metal (TM) or transition-metal oxide (TMO) on a

\footnotetext{
${ }^{a} \mathrm{KU}$ Leuven, University of Leuven, Department of Chemistry, Celestijnenlaan $200 f$ - box 2404, 3001 Leuven, Belgium. E-mail: markus.heyne@chem.kuleuven.be

${ }^{b}$ IMEC, Kapeldreef 75, 3001 Leuven, Belgium

${ }^{c}$ University of Antwerp, Department Chemistry, Universiteitsplein 1, 2610 Antwerp-Wilrijk, Belgium

$\dagger$ Electronic supplementary information (ESI) available. See DOI: 10.1039/c5tc04063a
}

substrate with subsequent sulfurization from a $\mathrm{S}$ source. ${ }^{9-13}$ The homogeneous $\mathrm{S}$ supply can also be achieved by using a gaseous precursor such as $\mathrm{H}_{2} \mathrm{~S} .{ }^{14-21}$ The present paper elucidates the mechanisms of $\mathrm{MoS}_{2}$ multilayer synthesis by the sulfurization technique. The influence of the process temperature, annealing time, and ramp rate is studied, as well as the nature of the pre-deposited layers $\mathrm{MoO}_{3}$, metallic Mo, and the nature of the substrate. The synthesis ambient was compared for mixtures of $\mathrm{H}_{2} \mathrm{~S} / \mathrm{H}_{2}$ vs. pure $\mathrm{H}_{2} \mathrm{~S}$. The grown films were characterized by various optical, morphological, and structural techniques. The highest quality $\mathrm{MX}_{2}$ films have been only demonstrated on atomically flat substrates such as graphene or other exfoliated $\mathrm{MX}_{2}$ substrate layers, ${ }^{22,23}$ but the deposition on amorphous substrates is desirable due to their availability for large area substrates such as $300 \mathrm{~mm}$ wafer. This paper establishes guidelines for the synthesis of horizontally aligned transitionmetal dichalcogenide multilayer thin films on $\mathrm{SiO}_{2}$.

\section{Experimental}

\section{TM and TMO deposition}

The Mo-based TM and TMO films were prepared by physical vapor deposition on top of thermal or native silicon oxide substrates. To deposit TMO, oxygen was added as reactive component in the PVD deposition. We studied a thick $5 \mathrm{~nm}$ Mo-film on $270 \mathrm{~nm}$ wet thermal silicon oxide (stack A), a thin 
$2 \mathrm{~nm}$ Mo-film on $270 \mathrm{~nm}$ wet thermal silicon oxide (stack B), and a $5 \mathrm{~nm}$ reactively sputtered $\mathrm{MoO}_{x}$ on thin native silicon oxide (stack C).

\section{Sulfurization of the TM and TMO films}

The samples were sulfurized $e x$ situ in a 6 inch rapid thermal processing (RTP) chamber ANNEALSYS-ONE-150 equipped with $\mathrm{H}_{2}$ and $\mathrm{H}_{2} \mathrm{~S}$ gas supply. For this purpose, the samples were placed on top of a SiC-coated graphite susceptor in the annealing chamber. The chamber was pumped to vacuum and then the temperature was increased to the target temperature $400{ }^{\circ} \mathrm{C}$, $600{ }^{\circ} \mathrm{C}$, or $800{ }^{\circ} \mathrm{C}$. The gas mixture of $10 \%$ or $100 \% \mathrm{H}_{2} \mathrm{~S}$ in $\mathrm{H}_{2}$ was injected until the pressure reached 100 mbar and kept under static conditions for the process duration of $5 \mathrm{~min}$ to $30 \mathrm{~min}$. Afterwards, the heating was stopped, the chamber was cooled down and pumped to vacuum again for $20 \mathrm{~min}$.

\section{Characterization of the films}

The films were analyzed by Rutherford backscattering spectrometry (RBS) to determine the amount of Mo and $S$ after the sulfurization. The accelerator at imec is a $6 \mathrm{SDH}$ Pelletron accelerator from the National Electrostatics Corporation (NEC). To this end, a He-beam with an energy of $1.523 \mathrm{MeV}$ and beam currents of $20 \mathrm{nA}$ to $40 \mathrm{nA}$ were used. The scattering angle was $170^{\circ}$ and the tilt angle was $11^{\circ}$. The used goniometer is described in literature. ${ }^{24}$ Before the measurement, the incident beam was calibrated to a reference material of an AlW/TiN/Si substrate. A representative spectra of $\mathrm{MoS}_{2}$ can be found in Fig. 1 . Raman spectroscopy with a LabRAM HR tool was used to characterized the films' quality using an excitation wavelength of $532 \mathrm{~nm}$ and a grating of 1800 grooves per mm, yielding a theoretical resolution of $0.3 \mathrm{~cm}^{-1}$. A scanning electron microscope (SEM) FEI Nova 200 was used to investigate the surface morphology. Transmission electron microscopy (TEM) cross-section images were obtained with a FEI Tecnai F30 ST at $200 \mathrm{kV}$ and plan-view images with $\operatorname{Titan}^{3} 60-300$ at $60 \mathrm{kV}$. The surface roughness was determined by an atomic force microscope (AFM) Dimension-Icon PT. Angle-resolved X-ray photoelectron spectra (ARXPS) were measured with a Theta 300 system

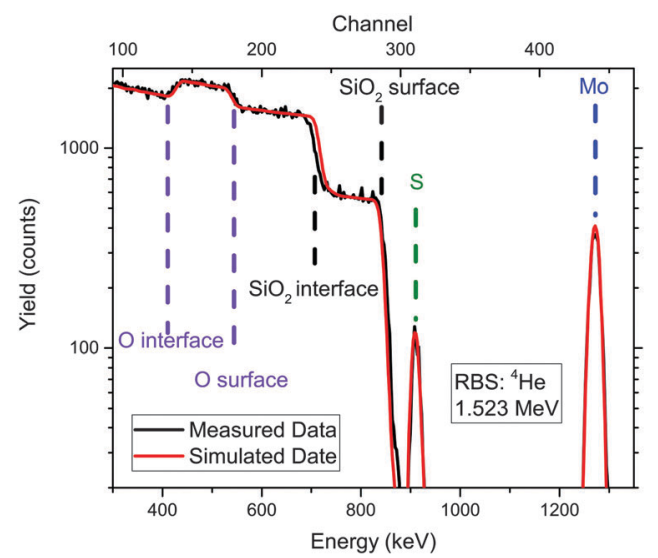

Fig. 1 RBS spectrum of a $\mathrm{MoS}_{2}$ film sulfurized from a stack of $2 \mathrm{~nm}$ $\mathrm{Mo} / 270 \mathrm{~nm} \mathrm{SiO} / \mathrm{Si}$ substrate. from ThermoInstruments. X-ray diffraction characterization was done with PANALYTICAL X'PERT.

\section{Results}

\section{Part I: growth parameter study}

Analysis of the pre-deposited material. TM and TMO films were deposited on $270 \mathrm{~nm}$ wet thermal silicon oxide substrates. The $5 \mathrm{~nm}$ (stack A) and $2 \mathrm{~nm}$ (stack B) metallic films oxidized partially or fully as soon as they were exposed to ambient. A third test specimen with $5 \mathrm{~nm} \mathrm{MoO}_{x}$ (stack C) on thin native silicon oxide was prepared by reactive sputtering. To determine the level of surface oxidation, stacks A, B, and C were analyzed by angle-resolved X-ray photoelectron spectroscopy (ARXPS). Information about the oxidation state was gained from the energy shift of the Mo 3d peak. ${ }^{25,26}$ Fig. 2 shows the all-integrated, normalized Mo 3d peaks in the XPS spectra for the three different stacks and the angle-resolved Mo 3d peak for stack A.

At $78^{\circ}$, the spectra for all three samples overlap, showing no metallic contribution, therefore indicating that all samples, TM and TMO, have an oxidized surface. By probing deeper under the surface, i.e. $21^{\circ}$ angle, it was found that only stack A shows a peak at the lower binding energy around $228 \mathrm{eV}$. The spectra for stacks B and C appear similar and they do not show this peak at low binding energy.

Sulfurization process. Starting from a typical $10 \% \mathrm{H}_{2} \mathrm{~S} / \mathrm{H}_{2}$ mixture as it is used in the $\mathrm{MoS}_{2}$ catalyst preparation, ${ }^{27}$ the temperature window between $400{ }^{\circ} \mathrm{C}$ and $800{ }^{\circ} \mathrm{C}$ was investigated. Afterwards, the influence of the $\mathrm{H}_{2}$ addition on the deposited film was explored. We subsequently tested the reaction time dependence and finally compared the influence of the underlying film on the growth conditions.

Influence of the processing temperature. The sulfurization of the stacks A, B, and C was carried out at temperatures of $400{ }^{\circ} \mathrm{C}$, $600{ }^{\circ} \mathrm{C}$, and $800{ }^{\circ} \mathrm{C}$. The chamber was heated in vacuum until the target temperature was reached, and subsequently the $\mathrm{H}_{2} \mathrm{~S}$ gas was introduced and kept in the chamber for 5 min under static conditions. Afterwards, the chamber was evacuated and cooled down passively. The samples were characterized by Rutherford
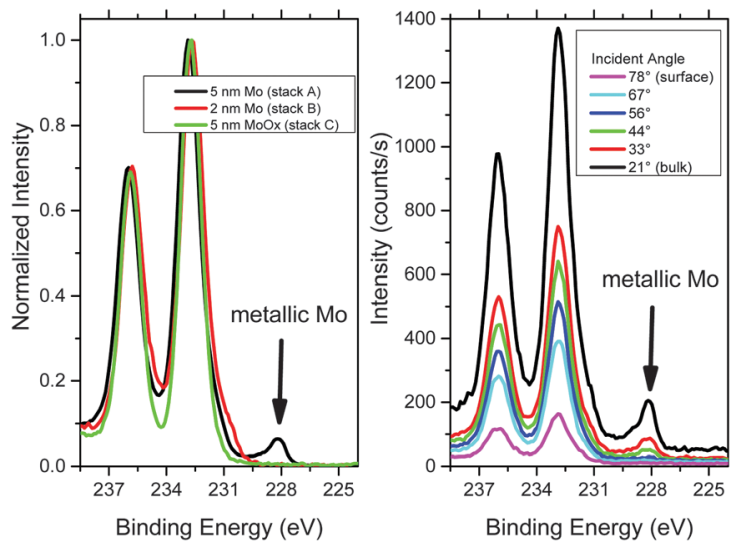

Fig. 2 ARXPS on stacks $A, B$, and $C$ before sulfurization showing oxidation of the layers and buried metallic Mo on stack $A$. 


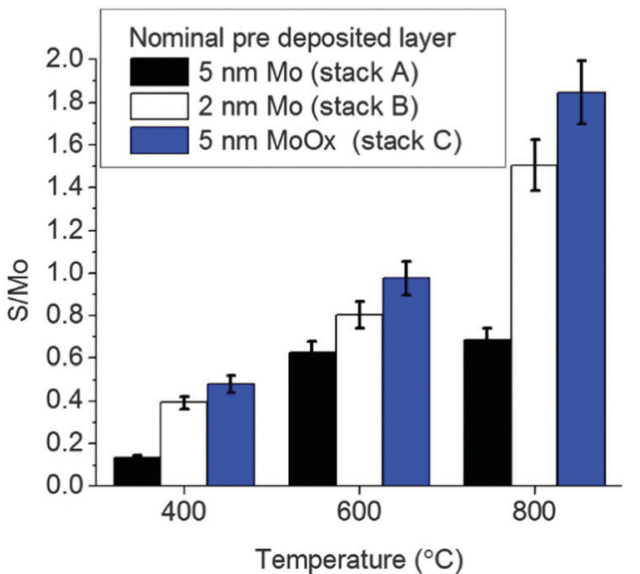

Fig. $3 \mathrm{~S} /$ Mo ratio of different stacks after 5 min sulfurization at different temperatures in a $10 \% \mathrm{H}_{2} \mathrm{~S} / \mathrm{H}_{2}$ mixture as determined by RBS.

backscattering spectrometry (RBS) and the ratio of the atomic areal density of S and Mo was calculated. The resulting S/Mo ratios are shown in Fig. 3.

After sulfurization at $400{ }^{\circ} \mathrm{C}$, the S/Mo ratio did not exceed 0.5 in any of the samples, increasing to the range $0.6-1.0$ for the $600{ }^{\circ} \mathrm{C}$-treated samples and up to a range 0.6-1.9 for the $800{ }^{\circ} \mathrm{C}$-treated samples. At $800{ }^{\circ} \mathrm{C}$, the sulfurization in stack C was higher than in stack B at $800{ }^{\circ} \mathrm{C}$, while in contrast, stack A could not be fully sulfurized in the $\mathrm{H}_{2} \mathrm{~S} / \mathrm{H}_{2}$ mixture even at $800{ }^{\circ} \mathrm{C}$ within the 5 min processing time in the $\mathrm{H}_{2} \mathrm{~S} / \mathrm{H}_{2}$ mixture. In the next paragraph, the influence of the hydrogen fraction in the gas mixture is described.

Influence of the hydrogen fraction in the sulfurization process. Samples of stack A, B, and C were heated to $600{ }^{\circ} \mathrm{C}$ and the $10 \% \mathrm{H}_{2} \mathrm{~S} / \mathrm{H}_{2}$ mixture or pure $100 \% \mathrm{H}_{2} \mathrm{~S}$ was injected in the chamber and kept under static conditions for five minutes. Afterwards, the samples were characterized by RBS and the S/Mo ratio was calculated. Stack A had a relatively low S/Mo ratio of below 0.8 for both annealing conditions (Fig. 4). In contrast, stacks B and $\mathrm{C}$ showed significant differences with the $10 \%$ mixture showing a S/Mo ratio of only 0.8 to 1.0 after 5 min, whereas the pure $\mathrm{H}_{2} \mathrm{~S}$ resulted in a ratio of about 2 .
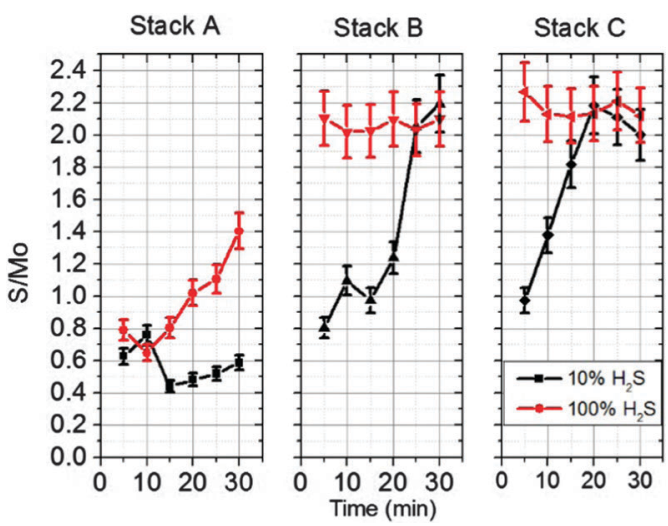

Fig. $4 \mathrm{~S} / \mathrm{Mo}$ ratios as calculated from the RBS atomic areal density, for sulfurization of $\mathrm{TM}$ and $\mathrm{TMO}$ at $600{ }^{\circ} \mathrm{C}$ in $\mathrm{H}_{2}$-diluted and pure $\mathrm{H}_{2} \mathrm{~S}$.

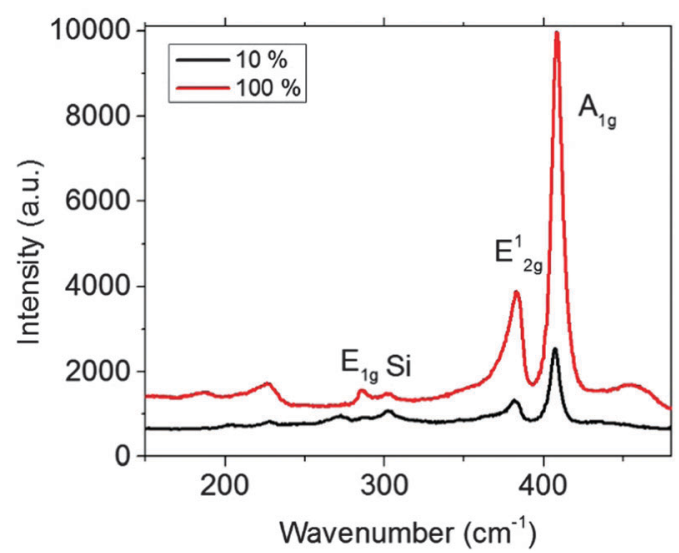

Fig. 5 Raman spectra of a stack B sample annealed for 5 min at $600{ }^{\circ} \mathrm{C}$ in $\mathrm{H}_{2}$-diluted and pure $\mathrm{H}_{2} \mathrm{~S}$.

The Raman spectra taken after sulfurization in $10 \%$ and $100 \%$ $\mathrm{H}_{2} \mathrm{~S}$ are depicted in Fig. 5. The samples annealed in pure $\mathrm{H}_{2} \mathrm{~S}$ showed higher $\mathrm{MoS}_{2}$-related peak intensity than in diluted $\mathrm{H}_{2} \mathrm{~S}$, further confirming the results from RBS.

We also investigated the time-dependence for TM/TMO film conversion. To this end, the stacks A, B, and C were sulfurized either in $10 \%$ or $100 \% \mathrm{H}_{2} \mathrm{~S}$ for different times, and the S/Mo ratio was determined by RBS as shown in Fig. 4.

Stack A of the $5 \mathrm{~nm}$ Mo shows a moderate time-dependency of the sulfurization under pure $\mathrm{H}_{2} \mathrm{~S}$, although not reaching the target value of $\mathrm{S} / \mathrm{Mo}=2$, while in the case of $\mathrm{H}_{2}$ dilution, the sulfurization is only marginally dependent on processing time. In contrast, stacks $\mathrm{B}$ and $\mathrm{C}$ show significant time-dependent sulfurization under $\mathrm{H}_{2}$ dilution and even immediate stoichiometric sulfurization already after 5 minutes processing time in the case of pure $\mathrm{H}_{2} \mathrm{~S}$. The sulfurization under $\mathrm{H}_{2}$ dilution was slower than in pure $\mathrm{H}_{2} \mathrm{~S}$ in all cases studied.

Annealing with optimized conditions. Based on the fact that stack A required a sulfurization temperature of $800{ }^{\circ} \mathrm{C}$ and pure $\mathrm{H}_{2} \mathrm{~S}$ gas for $30 \mathrm{~min}$ to reach a S/Mo close to 2, these conditions were applied to different initial thicknesses of deposited Mo on $\mathrm{SiO}_{2}$ and characterized by RBS after the sulfurization process. Fig. 6 shows that the S/Mo ratio as calculated from Mo and $\mathrm{S}$ amount is between 1.8 and 2 and thus, stoichiometric. Layers of initially $5 \mathrm{~nm}$ metallic Mo resulted in approximately $25 \mathrm{~nm}$ $\mathrm{MoS}_{2}$ films.

\section{Part II: $\mathrm{MoS}_{2}$ plane orientation}

Effect of ramp rate and interlayer oxide. The surface topology of the stacks B and C was compared by scanning electron microscopy (SEM) and atomic force microscopy (AFM) after annealing without $\mathrm{H}_{2} \mathrm{~S}$ and after the sulfurization process with $100 \% \mathrm{H}_{2} \mathrm{~S}$. The results are illustrated in Table 1, Fig. S1 and S2 (ESI $\dagger$ ).

The as-deposited metal and metal-oxide films had an initial RMS roughness of $0.3 \mathrm{~nm}$ to $0.4 \mathrm{~nm}$. After annealing in vacuum, the samples of stack B roughened. Annealing in $100 \% \mathrm{H}_{2} \mathrm{~S}$ increased the surface roughness even more. The arithmetic roughness parameter $R_{\mathrm{a}}$ of the $\mathrm{H}_{2} \mathrm{~S}$ annealed stack B was $R_{\mathrm{a}}=2 \mathrm{~nm}$. 


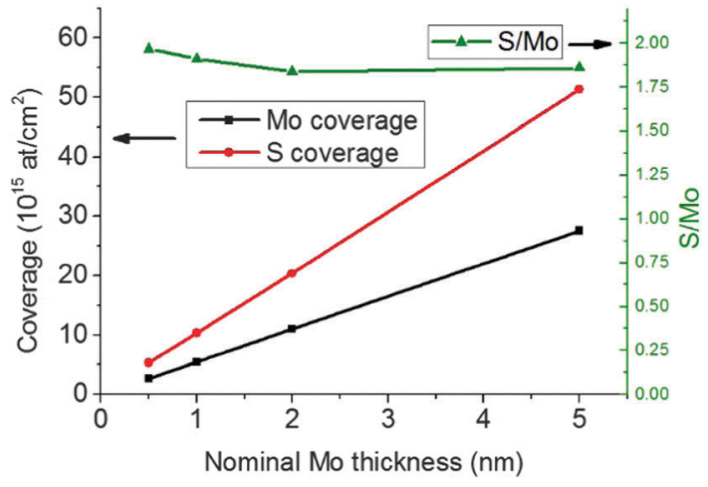

Fig. 6 Coverage of $\mathrm{Mo}$ and $\mathrm{S}$ and the $\mathrm{S} / \mathrm{Mo}$ ratio after $800^{\circ} \mathrm{C}$ sulfurization in $100 \% \mathrm{H}_{2} \mathrm{~S}$ for 30 min as a function of the initial sputtered Mo thickness determined by RBS.

Table 1 Comparison of the surface roughness of different stacks after sulfurization at $800{ }^{\circ} \mathrm{C}$ in $100 \% \mathrm{H}_{2} \mathrm{~S}$ for $30 \mathrm{~min}$. The scanned area was $2 \times 2 \mu \mathrm{m}^{2}$

Pristine

In contrast, stack $\mathrm{C}$ with the TMO on the native oxide showed less roughening than stack $\mathrm{B}$ in vacuum as well as in $\mathrm{H}_{2} \mathrm{~S}$. The roughness of stack C was only $R_{\mathrm{a}}=1.5 \mathrm{~nm}$. Hence, the samples with the wet silicon oxide underneath roughened to a larger extent than the samples grown on native silicon oxide.

A smooth surface is important for potential integration of planar electronic devices. To investigate this, the samples of stack B and C were measured before and after the sulfurization process.

Significant roughening can be seen after the $\mathrm{MoS}_{2}$ synthesis process on both sample surfaces, with hillocks appearing on the surface. The sulfurized stack B showed a larger density of these hillocks than stack $\mathrm{C}$, and these bumps were higher than $20 \mathrm{~nm}$ after sulfurization. The TEM image in Fig. 7 shows that a delamination occurred at the interface between $\mathrm{MoS}_{2}$ and $\mathrm{SiO}_{2}$ substrate. Stack B showed more delamination sites than stack C and hence, $\mathrm{MoS}_{2}$ on wet thermal oxide formed more hillocks than on native $\mathrm{SiO}_{2}$.

Underlying substrate. The role of the underlying substrate on the basal plane arrangement will be studied in this section. To this end, stacks $\mathrm{B}$ and $\mathrm{C}$ were sulfurized at $600{ }^{\circ} \mathrm{C}$ in pure $\mathrm{H}_{2} \mathrm{~S}$. The TEM cross section images are shown in Table 2.

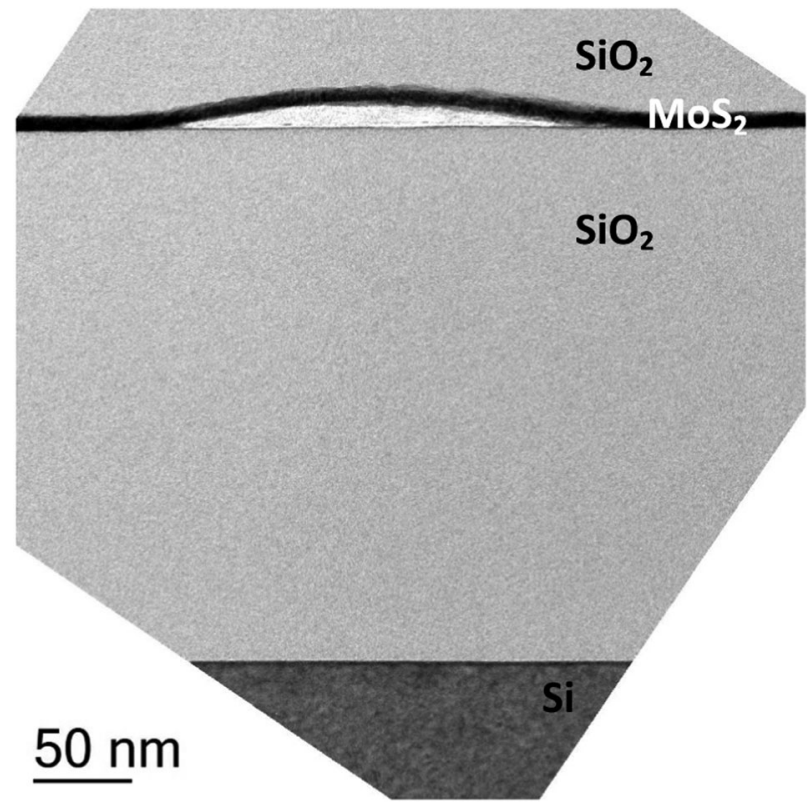

Fig. 7 TEM image showing delamination of the $\mathrm{MoS}_{2}$ film (dark) from the $\mathrm{SiO}_{2}$ substrate (bright).

Stack B reveals two preferential layer orientations after the $600{ }^{\circ} \mathrm{C}$ sulfurization. While the surface layers appear rather horizontal, the bulk material is oriented more vertical to the substrate. The layered structure can be seen in the whole film and thus, the $\mathrm{H}_{2} \mathrm{~S}$ precursor is diffusing throughout the whole film, even at $600{ }^{\circ} \mathrm{C}$.

However, stack $\mathrm{C}$ revealed a horizontally layered structure over the full thickness after the $600{ }^{\circ} \mathrm{C}$ sulfurization. At the same time, the interface oxide of 3-4 $\mathrm{nm}$ was thicker than the usual native oxide of around $1 \mathrm{~nm}$, meaning that the oxide thickness has increased during the high temperature step. A similar horizontal assembling like in stack B could only be reached at a higher temperature of $800{ }^{\circ} \mathrm{C}$, leading us to conclude that the interfacial oxide thickness and substrate type result in an interplay with different sulfurization temperatures to different basal plane assemblies. On thin silicon oxide, the horizontal alignment took place at lower temperature than on thick $\mathrm{SiO}_{2}$.

The lattice spacing derived from the cross-section TEM images in Table 2 are between $0.60 \mathrm{~nm}$ and $0.65 \mathrm{~nm}$. The accuracy is low due to the thin layer and irregular oriented planes. The range of the spacing correspond to the expected $0.61 \mathrm{~nm}$ for the stoichiometric $\mathrm{MoS}_{2}$ in $2 \mathrm{H}$ phase.

\section{Part III: $\mathrm{MoS}_{2}$ quality}

Hydrophobicity and crystallinity. Ideal horizontally layered $\mathrm{MoS}_{2}$ is expected to be hydrophobic due to the sulfur surface termination. In contrast, material exposing many edges to the top is expected to be hydrophilic due to the reactive nature of the edges. Table 3 shows a contact angle of $93^{\circ}$ for the $\mathrm{MoS}_{2}$ deposited at $800{ }^{\circ} \mathrm{C}$, which demonstrates the hydrophobic character as compared to $\mathrm{SiO}_{2}$ or $\mathrm{MoO}_{3}$ surface. After the sulfurization under the optimized conditions of $800{ }^{\circ} \mathrm{C}$ for 
Sulfurized stack B at $600{ }^{\circ} \mathrm{C}$ in $\mathrm{H}_{2} \mathrm{~S}: \mathrm{MoS}_{2}$ on thick $\mathrm{SiO}_{2}$

Sulfurized stack C at $600{ }^{\circ} \mathrm{C}$ in $\mathrm{H}_{2} \mathrm{~S}: \mathrm{MoS}_{2}$ on thin $\mathrm{SiO}_{2}$
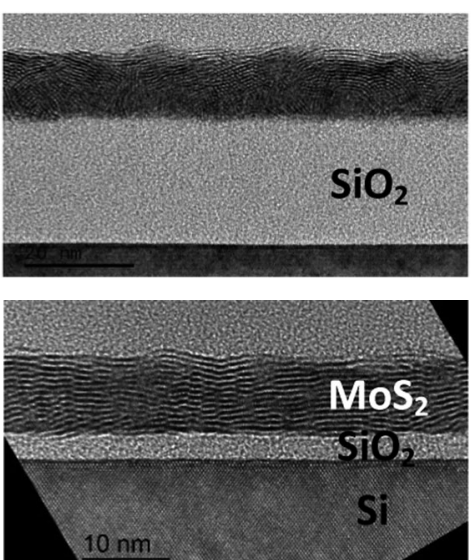

Sulfurized Stack B at $800{ }^{\circ} \mathrm{C}$ in $\mathrm{H}_{2} \mathrm{~S}$ : $\mathrm{MoS}_{2}$ on thick $\mathrm{SiO}_{2}$

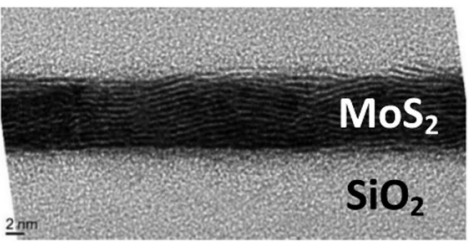

Table 3 Contact angles on a $\mathrm{SiO}_{2}$ substrate, a molybdenum oxide sample, and a $800{ }^{\circ} \mathrm{C}$ sulfurized $\mathrm{MoS}_{2}$ sample

\begin{tabular}{|l|l|l|}
\hline $\mathrm{SiO}_{2}$ & $\mathrm{MoO}_{3}$ & $\mathrm{MoS}_{2}$ \\
\hline & & \\
\hline & & \\
\hline & & \\
\hline & & \\
\hline
\end{tabular}

$30 \mathrm{~min}$ in $100 \% \mathrm{H}_{2} \mathrm{~S}$, the sample was characterized by glancingincidence XRD (GIXRD). The film showed the characteristic $\mathrm{MoS}_{2}(002)$ peak around $14.3^{\circ}$ as can be seen from Fig. $8 .^{28,29}$

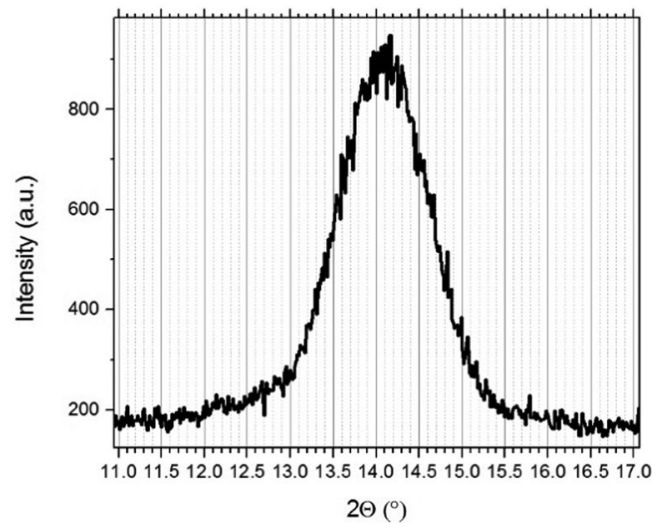

Fig. 8 GIXRD spectrum of the $\mathrm{MoS}_{2}(002)$-related peak synthesized from stack $\mathrm{C}$ at $800{ }^{\circ} \mathrm{C}$ in $100 \% \mathrm{H}_{2} \mathrm{~S}$ during $30 \mathrm{~min}$.
Plan-view TEM images. Besides the qualitative and quantitative analysis of the $\mathrm{MoS}_{2}$ crystal structure, the determination of the crystal grain size is essential since grain boundaries act as defects for charge transport, negatively impacting the mobility of these materials. To determine the grain size, the $\mathrm{MoS}_{2}$ had to be transferred to a thin e-beam-transparent membrane suitable for TEM imaging. To this purpose, the samples were immersed in water and the films peeled off from the substrates. ${ }^{30}$

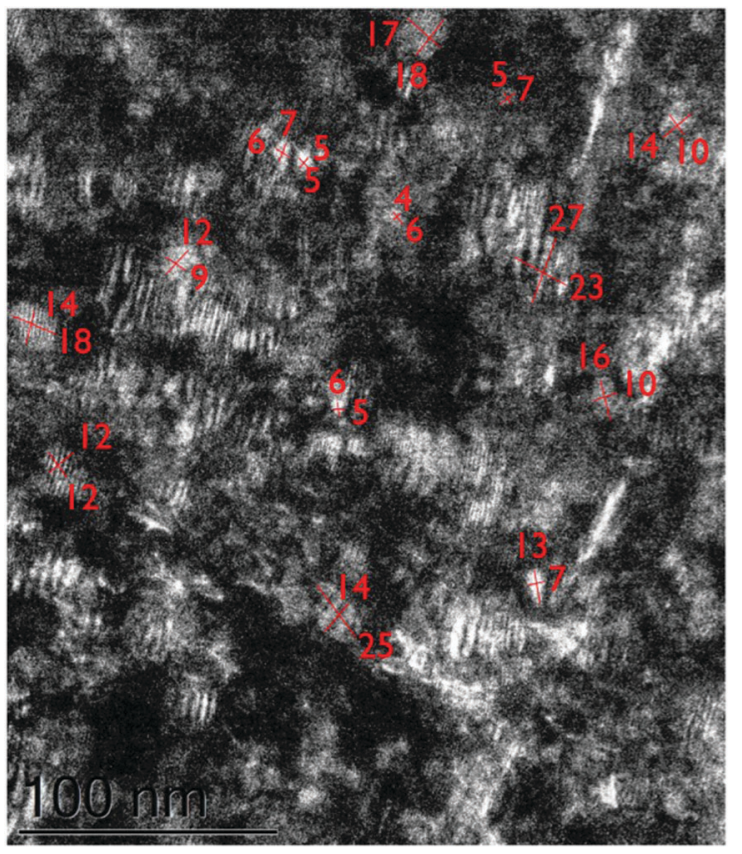

Fig. 9 TEM image from stack $C$ annealed at $800{ }^{\circ} \mathrm{C}$ in dark field mode indicating crystal sizes in the $10-25 \mathrm{~nm}$ range. 


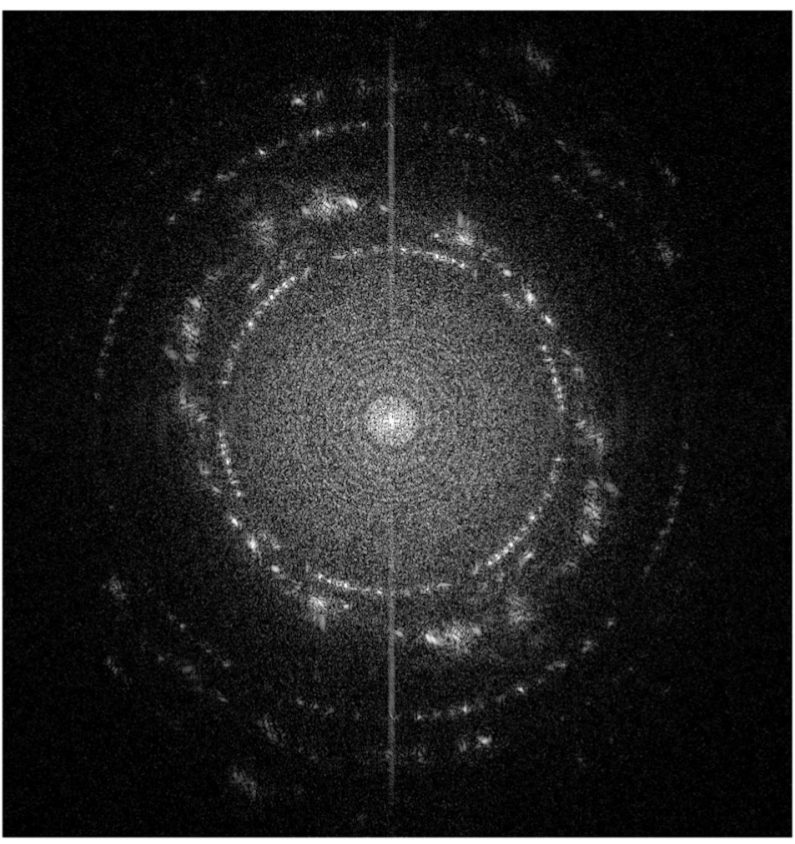

Fig. 10 FFT of a plan-view image of stack $\mathrm{C}$ annealed at $800^{\circ} \mathrm{C}$ for $30 \mathrm{~min}$.

Subsequently the films could be transferred to a thin $\mathrm{Si}_{3} \mathrm{~N}_{4}$ membrane which is nearly transparent for the electron beam. The image in Fig. 9 shows grain sizes in the 10 to $25 \mathrm{~nm}$ range. Due to varying orientation of the crystal planes as can be seen on the cross-sectional TEM images in Table 2 and the electron scattering on the underlying $\mathrm{Si}_{3} \mathrm{~N}_{4}$, an atomic pattern was barely observable on the plan-view images. Electron diffraction and Fast-Fourier transformed images in Fig. 10 show that the $\mathrm{MoS}_{2}$ is nearly oriented along [0001] with random in-plane orientation of the grains and probably fully in the $2 \mathrm{H}$ phase.

Surface chemical analysis. The XPS spectra of the Mo $3 \mathrm{~d}$ peak are depicted in Fig. 11. After the sulfurization at $800{ }^{\circ} \mathrm{C}$, a peak shift to lower binding energies characteristic for $\mathrm{MoS}_{2}$, can be seen. The peak appearing around $227 \mathrm{eV}$ is related to the $\mathrm{S} 2 \mathrm{~s}$ region.

Photoluminescence. A quality feature of thin layers of TMD materials is the photoluminescence (PL) appearing due to the direct bandgap transition. ${ }^{31-34}$ In Fig. 12 the intensity change in the direct excitonic transitions A1 and B1 for different starting Mo thicknesses is plotted, showing a higher PL for thinner sulfurized layers. This evidences the band gap opening towards thinner layers and proves an acceptable material quality.

\section{Discussion}

\section{Part I: growth parameter study}

Analysis of deposited material. Only the thick stack A shows a Mo photoelectron peak at lower binding energy indicating a metallic contribution. Together with the angle-resolved measurements, this revealed that the surface was oxidized in air and only the bottom part of the layer at the interface with

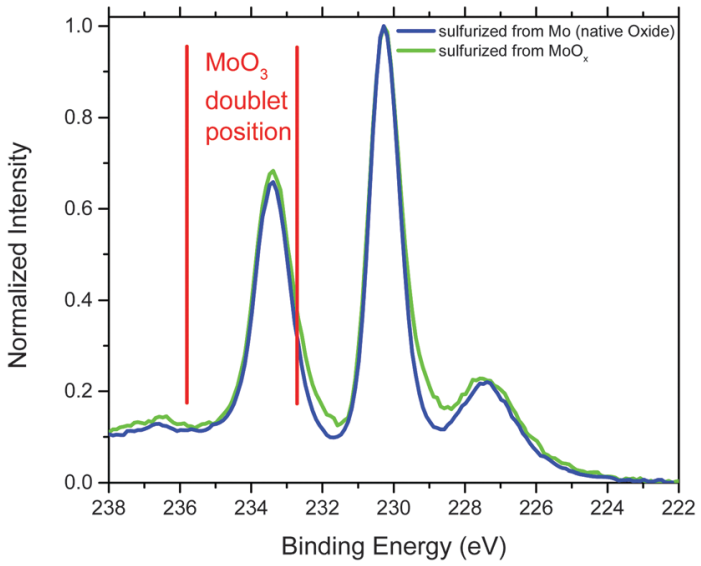

Fig. 11 Mo 3d peak in XPS spectra for pristine samples and $800{ }^{\circ} \mathrm{C}$ in $100 \% \mathrm{H}_{2} \mathrm{~S}$ sulfurized samples.

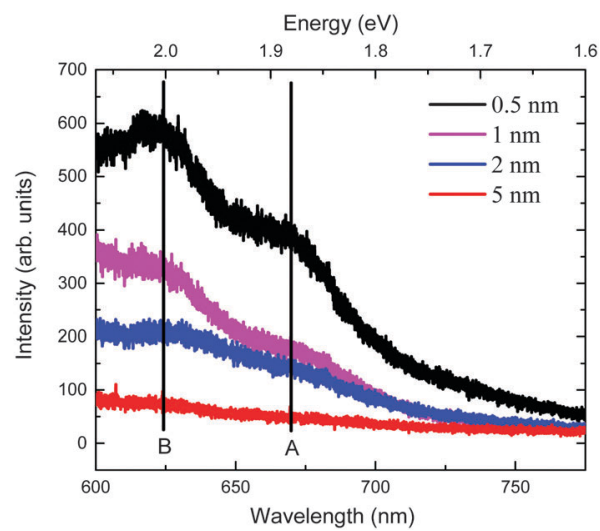

Fig. 12 Photoluminescence measured on samples synthesized at $800{ }^{\circ} \mathrm{C}$ in $100 \% \mathrm{H}_{2} \mathrm{~S}$ for 30 min from different starting thicknesses.

the substrate was metallic. In contrast, similar spectra for stacks B and C indicated that the chemical state was uniform throughout the entire film, i.e. stack B oxidized completely in air. The formed oxides appear in the XPS as a doublet at relatively high binding energy close to the one of $\mathrm{MoO}_{3}$ at $233.1 \mathrm{eV}$. This is why the synthetic as well as the native oxides can be assumed to have the trioxide structure. Thus, the TMO of stack B and C was comparable and differed mainly in the underlayer, being a thick thermal oxide in stack $\mathrm{B}$ and a thin native oxide in stack $\mathrm{C}$.

The root-mean-square (RMS) roughness in the range of 0.2 to $0.3 \mathrm{~nm}$ was slightly higher than expected on a polished Si surface $(0.1 \mathrm{~nm})$, but still reasonable for an oxidized substrate covered with a PVD metallic film. The stack roughness of $0.3 \mathrm{~nm}$ was acceptable taking into account a $\mathrm{MoS}_{2}$ monolayer thickness of $0.7 \mathrm{~nm}$.

\section{Sulfurization process optimization}

Temperature. Higher temperature resulted in a higher sulfurization degree. Stacks $\mathrm{B}$ and $\mathrm{C}$ could be sulfurized almost stoichiometrically at $800{ }^{\circ} \mathrm{C}$ in the $\mathrm{H}_{2} \mathrm{~S} / \mathrm{H}_{2}$ mixture, while lower temperatures only resulted in a partial sulfurization. 
Stack A containing the metallic Mo could not be sulfurized in the mixture, not even at high temperature.

The absolute sulfur content in the sulfurized stack A was compared with the Mo amount in stacks B and C. Stack B represented a metallic film being completely oxidized in air. Thus, the thicker stack A could be assumed to be a double stack of native top Mo-oxide comparable to stack B and $\mathrm{C}$ and a metallic part underneath. The ratio of the amount of sulfur to the amount of oxidized Mo was $0.2,1.4$, and 1.6 for $400{ }^{\circ} \mathrm{C}$, $600{ }^{\circ} \mathrm{C}$, and $800{ }^{\circ} \mathrm{C}$, respectively. This is comparable to the $\mathrm{S} /$ Mo ratios for stacks $\mathrm{B}$ and $\mathrm{C}$, indicating that at $600{ }^{\circ} \mathrm{C}$ mainly the oxidized part was sulfurized, but not the metallic part. From these observations, we conclude that the sulfurization of $\mathrm{MoO}_{3}$ proceeds at lower temperature than the sulfurization of metallic Mo.

The involved reactions are the following:

$$
\begin{gathered}
\mathrm{MoO}_{3(\mathrm{~g})}+3 \mathrm{H}_{2} \mathrm{~S}_{(\mathrm{g})} \rightleftharpoons \mathrm{MoS}_{2(\mathrm{~s})}+3 \mathrm{H}_{2} \mathrm{O}_{(\mathrm{g})}+\mathrm{S}_{(\mathrm{s})} \\
\mathrm{Mo}_{(\mathrm{s})}+2 \mathrm{H}_{2} \mathrm{~S}_{(\mathrm{g})} \rightleftharpoons \mathrm{MoS}_{2(\mathrm{~s})}+2 \mathrm{H}_{2(\mathrm{~g})}
\end{gathered}
$$

The software module reaction equations from the package HSC Chemistry was used to calculate the change in Gibbs free energy for the reactions (I) and (II) by simply calculating the differences in enthalpy and entropy taken from a database. The results in the temperature range from $0{ }^{\circ} \mathrm{C}$ to $1000{ }^{\circ} \mathrm{C}$ are depicted in Fig. 13. The Gibbs free energy is negative over a large temperature range and thus, both reactions should proceed spontaneously. Reaction (II) has a higher Gibbs free energy than reaction (I) in the high temperature range above $200{ }^{\circ} \mathrm{C}$. Hence, the sulfurization of metallic Mo requires higher temperature or longer annealing time than the sulfurization of $\mathrm{MoO}_{3}$. This was confirmed by our observation that the metalcontaining film remained non-stoichiometric, even after a long sulfurization processes.

The data also indicated that stack $\mathrm{C}$ was sulfurized to a higher degree than stack B. This shows that their behavior was slightly different despite their similar chemical nature as the XPS data have shown. The major difference in these samples was the substrate, i.e. thin (stack C) or thick (stack B) silicon oxide

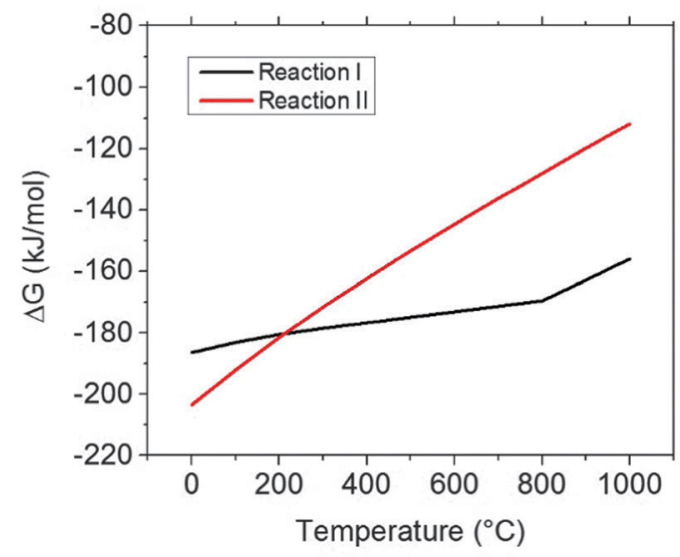

Fig. 13 Change in Gibbs free energy for reaction (I) and (II) as a function of temperature. underneath. In case of the thin oxide, reaction byproducts could diffuse easier through the thin native oxide than through the thick native oxide and scavenged by the silicon underneath.

Partial Pressure and Time. Hydrogen is reported to reduce $\mathrm{MoS}_{2}$ at temperatures above $500{ }^{\circ} \mathrm{C},{ }^{35}$ although this reaction is energetically unfavorable with $\Delta G=+200 \mathrm{~kJ} \mathrm{~mol}^{-1}, \mathrm{H}_{2}$ was excluded from the process gasses by switching to pure $\mathrm{H}_{2} \mathrm{~S}$. As demonstrated, the sulfurization with pure $\mathrm{H}_{2} \mathrm{~S}$ was faster compared to the sulfurization with the $10 \%$ mixture, indicating that hydrogen must have hampered the sulfurization reaction. This can be attributed to different mechanisms. ${ }^{36}$ We assume that the sulfurization reaction for either oxidized or metallic Mo occurs alongside reactions (I) and (II), respectively.

Reaction (I) has a change in Gibbs free energy of $-173 \mathrm{~kJ} \mathrm{~mol}^{-1}$, whereas reaction (II) has $-145 \mathrm{~kJ} \mathrm{~mol}^{-1}$. Thus, both reaction are exergonic and proceed spontaneously. If hydrogen is added to reaction (II), the concentration on the product side will increase and will slow down the reaction. While the mixture with hydrogen does not show any time-dependence in Fig. 4, the pure $\mathrm{H}_{2} \mathrm{~S}$ showed an increasing sulfurization degree with time, although it did not reach stoichiometry in this time-frame at this temperature. Thus, hydrogen plays a crucial role in the sulfurization of the samples with the metallic core.

In contrast, stacks $\mathrm{B}$ and $\mathrm{C}$ showed a time-dependent $\mathrm{S} / \mathrm{Mo}$ ratio in case of the $\mathrm{H}_{2} \mathrm{~S} / \mathrm{H}_{2}$ mixture, but a constant, stoichiometric ratio in case of the pure $\mathrm{H}_{2} \mathrm{~S}$. In reaction (I), no hydrogen is involved, meaning that the faster process can only be explained by the increase of the $\mathrm{H}_{2} \mathrm{~S}$ partial pressure from $10 \mathrm{mbar}$ to $100 \mathrm{mbar}$. The higher $\mathrm{H}_{2} \mathrm{~S}$ amount induced a faster sulfurization while the hydrogen did not influence the chemical reaction.

From the previous experiments, it can be concluded that a high sulfurization temperature, longer sulfurization time, and higher $\mathrm{H}_{2} \mathrm{~S}$ partial pressure resulted in enhanced material quality. For metallic films the reaction kinetics were influence by the hydrogen partial pressure. Although thin films of stacks B and $\mathrm{C}$ could be sulfurized at a temperature of $600{ }^{\circ} \mathrm{C}$, the sulfurization of thicker films like in stack A was not possible within $30 \mathrm{~min}$ annealing time. Therefore, the sulfurization temperature was further increased to $800{ }^{\circ} \mathrm{C}$ in order to facilitate a full sulfurization of the thicker films and to ensure the full conversion of metallic Mo.

To verify the full sulfurization, starting layers of different thicknesses were prepared and annealed under similar conditions. The Mo and S areal densities show a linear trend proportional to the initially deposited Mo thickness. This confirms that the higher temperature is necessary in order to allow the full sulfurization of thicker, metallic layers as well.

\section{Part II: $\mathrm{MoS}_{\mathbf{2}}$ plane orientation}

After optimization of the annealing conditions for metallic and metal-oxide-based layers, the deposited films were characterized to gain an understanding of the mechanisms which are driving the sulfurization. In the ideal case, two-dimensional films are entirely flat. The surface topology of our samples was characterized by SEM and AFM after annealing, showing different topographical 
roughness for the different conditions. Whereas stacks A and B revealed surface roughening after annealing, stack $\mathrm{C}$ showed better wetting on the underlayer, and this effect appeared after annealing in vacuum as well as in $\mathrm{H}_{2} \mathrm{~S}$ environment. However, the latter showed stronger roughening, which indicates that the roughening is related to both the substrate and the environment as the images in Table 1 demonstrate.

The interface material between the $\mathrm{MoS}_{2}$ film and the substrate was in all cases $\mathrm{SiO}_{2}$, thus the surface energy of the two substrates can be assumed to be similar. However, the alignment of the $\mathrm{MoS}_{2}$ basal planes differed between the samples with thick and thin $\mathrm{SiO}_{2}$. The $\mathrm{MoS}_{2}$ films on the thick wet-grown $\mathrm{SiO}_{2}$ show macroscopically rough surface after annealing, whereas the $\mathrm{MoS}_{2}$ films on the thin $\mathrm{SiO}_{2}$ had a conformal surface as judged from the SEM images. A possible explanation is the formation and release or consumption of reaction byproducts. The sulfurization reactions release gaseous products which is $\mathrm{H}_{2} \mathrm{O}$ in reaction (I) and $\mathrm{H}_{2}$ in reaction (II). The deposition process occurring in different steps. Initially, the $\mathrm{H}_{2} \mathrm{~S}$ approaches the surfaces and the reaction starts there. Subsequently the $\mathrm{H}_{2} \mathrm{~S}$ needs to diffuse through the layers to react deeper into the sublayers. During this reaction, gaseous products will be formed which have to leave the film again. In case of metallic layers, this formed compound is $\mathrm{H}_{2}$ which is small enough to easily escape towards the surface. However, the sulfurization of oxide results in $\mathrm{H}_{2} \mathrm{O}$ formation which cannot easily escape the surface through the $\mathrm{MoS}_{2}$, but can only slowly diffuse through the $\mathrm{SiO}_{2}$ substrate. ${ }^{37-39}$ If the diffusion at $700{ }^{\circ} \mathrm{C}$ was to slow, the $\mathrm{H}_{2} \mathrm{O}$ might have accumulated at the $\mathrm{MoS}_{2}$ /substrate interface and lifted of the film which resulted in rough topology on the $\mathrm{MoS}_{2}$ on thick silicon oxide or even delamination of the films. In the case of very thin $1.2 \mathrm{~nm}$ oxide, the $\mathrm{H}_{2} \mathrm{O}$ could diffuse with lower activation energy through the thin barrier and oxidize the silicon underneath. Hence, the substrate may have acted as a scavenger for the reaction products of the sulfurization and the roughness of the layers and simultaneously their horizontal arrangement could be improved.

The roughness was induced by the hillocks on the sample surface and by the $\mathrm{MoS}_{2}$ film itself. However, the surface images showed that the microroughness was superimposed to the hillocks which formed during the delamination of the $\mathrm{MoS}_{2}$ films from the $\mathrm{SiO}_{2}$ substrates.

The $R_{\mathrm{a}}$ determined as the arithmetic average from the absolute values reveals another difference between the samples. The sulfurized stack B showed a higher roughness of around $2 \mathrm{~nm}$, whereas the TMO sulfurized stack C showed a roughness of $1.5 \mathrm{~nm}$. The scavenged water or oxygen in the Si underneath might prevent the outgassing of water to the film surface and, as such, the chemical reaction is completed faster in stack $\mathrm{C}$ and it favors the plane alignment horizontal to the interface in a given reaction time. Stack B with the thicker oxide scavenges less water and thus the reaction takes longer before the planes realign.

Based on these observations, we conclude that the annealing on a thick $\mathrm{SiO}_{2}$ layer already introduced roughness in vacuum by dewetting. ${ }^{40} \mathrm{~A} \mathrm{H}_{2} \mathrm{~S}$ flow during this annealing further increased this effect by releasing reaction byproducts. The basal planes were more horizontal when an underlying reservoir area for collecting reaction products was provided.

\section{Part III: $\mathrm{MoS}_{2}$ quality}

Hydrophobicity. The surface wetting by water gives indications on the material quality. The wetting angle as well as the TEM observation of the $800{ }^{\circ} \mathrm{C}$ annealed sample are in agreement with results from literature, ${ }^{37}$ revealing the hydrophobic nature of the surface which is correlated to the growth temperature and thus also with the $\mathrm{MoS}_{2}$ structure. ${ }^{41}$ As shown in the previous sections, material grown at low temperature which might be only partially sulfurized and did not go through the crystallization process yet, tends to form random structures oriented to the reactants' diffusion direction. This results in the exposure of many edge sites at the surface leading to a high surface energy and thus, a more hydrophilic behavior. In contrast, higher temperature favors the crystallization resulting in horizontal planes in which the edge exposure is decreased and hence results in low-energy, hydrophobic surfaces. This observation also confirms the improved quality of the material from the high temperature growth.

Crystal morphology. Comparing the assembly of the basal planes, the $600{ }^{\circ} \mathrm{C}$ sulfurization on thin native silicon oxide resulted in preferential horizontal arrangement of the basal planes. In contrast, layers on thick $\mathrm{SiO}_{2}$ tend to form relatively rough films with random orientation. The chemical reaction to $\mathrm{MoS}_{2}$ is faster and more time is given to the recrystallization process when using 30 min processing time. During the crystallization, the basal planes orient in a way to reduce their surface energy. Hence, on perfectly flat substrates such as native or thermally grown $\mathrm{SiO}_{2}$, the basal planes will assemble parallel to the substrates and the following $\mathrm{MoS}_{2}$ planes will orient in alignment with the basal planes. ${ }^{42}$ Similar behavior is predicted for other flat substrates which could take up $\mathrm{H}_{2} \mathrm{O}$ in a high temperature process or which are permeable for byproducts of the sulfurization reaction.

Comparing the sulfurization between a fully oxidized layer and a partially oxidized layer with metallic components, the oxidized films resulted in better film quality at lower temperature. Since the metallic layer needs a higher temperature and is more densely packed, the $\mathrm{MoS}_{2}$ grown from metallic material suffers from the slow pace of material transport. The $\mathrm{H}_{2} \mathrm{~S}$ molecules need to diffuse through the metallic layer and induce an additional volume expansion of a factor of 4 which leads to mass transport and distort the structure itself. In contrast, the $5 \mathrm{~nm} \mathrm{MoO}_{3}$ layers are found to expand only by about a factor of 1.6 as is shown in Table 2. The observations from stack A confirm this. The TEM images of the thicker sulfurized stacks showed horizontally oriented crystals on the top. This top structure was directly sulfurized from the native oxide, which proceeds fast and efficient even at the relatively low temperature of $600{ }^{\circ} \mathrm{C}$. However, the incompletely sulfurized bulk was vertically layered. This observation suggested that the TMD layered structure orient towards the diffusion direction of the gaseous reaction source material and products. Only after the reaction has finished and no more reactants force the plane 
direction, the crystallization process takes place and the planes realign according to the interface with the underlying material. This confirms earlier reports exhibiting relatively random $\mathrm{MoS}_{2}$ orientation on rough and thick $\mathrm{SiO}_{2}{ }^{43-47}$

Surface chemical state. The XPS spectra of the as-deposited metal-oxide and metal films can be interpreted mainly as $\mathrm{MoO}_{3}$ and $\mathrm{MoO}_{3} /$ metallic layer, respectively. The NIST database reports the Mo 3d5/2 doublet for $\mathrm{MoO}_{3}$ around $232.5 \mathrm{eV}^{25}$ and the metallic Mo peak is located at $228 \mathrm{eV}{ }^{48}$ In contrast, $\mathrm{MoO}_{2}$ is reported around $229.3 \mathrm{eV}$ and could not be clearly identified in the $\mathrm{MoO}_{x}$ layers. In the sulfurized $\mathrm{MoS}_{2}$ films, the relatively high binding energy of the Mo $3 \mathrm{~d}$ doublet of $\mathrm{MoS}_{2}$ suggests a mainly $2 \mathrm{H}$ polytype since the $1 \mathrm{~T}$ polytype is usually located at lower binding energies. ${ }^{49}$ This is also in agreement with the $2 \mathrm{H}$ lattice distances measured from the TEM cross-sections. ${ }^{50,51}$ The $2 \mathrm{H}$ polytype is expected to be semiconducting, whereas the $1 \mathrm{~T}$ is a more metallic phase making the material promising for integration as a transistor channel. The absence of $\mathrm{MoO}_{3}$-related peaks in the XPS spectra confirm the full sulfurization of the material in the $\mathrm{H}_{2} \mathrm{~S}$ atmosphere with the optimized conditions.

Indirect-to-direct band gap transition. Another characteristic of thin van-der-Waals bonded layers are the layer-dependent property changes. A special TMD material characteristic is evolution of its PL for monolayers due to the indirect-to-direct bandgap transition. We applied the high temperature recipe with the pure $\mathrm{H}_{2} \mathrm{~S}$ gas to different thicknesses of TM/TMO. The thinner $\mathrm{Mo} / \mathrm{MoO}_{3}$ layers showed higher PL after the sulfurization process. This evolving PL indicates the efficiency of the sulfurization process and can be used as an indicator for further process optimization. Considering the fact that an initial Mo thickness of $0.5 \mathrm{~nm}$ corresponds to 3 monolayers, the PL could be further enhanced by using double- or monolayer structures.

\section{Conclusions}

In this work we investigated the sulfurization of thin transitionmetal layers in $\mathrm{H}_{2} \mathrm{~S}$ and $\mathrm{H}_{2} \mathrm{~S} / \mathrm{H}_{2}$ mixtures. The reaction kinetics in TMO were determined by the $\mathrm{H}_{2} \mathrm{~S}$ partial pressure, whereas the sulfurization of metallic TM depends on the hydrogen content as well, since the presence of hydrogen slows down the sulfurization reaction in metallic TMs. The best TMD layers were obtained in pure $\mathrm{H}_{2} \mathrm{~S}$ ambient. The full sulfurization of metallic TM requires high temperatures of $800{ }^{\circ} \mathrm{C}$ resulting in higher film expansion than in the case of sulfurizing TMOs, which can be sulfurized at a lower temperature of $600{ }^{\circ} \mathrm{C}$.

Gaseous byproducts of the sulfurization reaction escape in between the planes and affect their orientation during the ongoing sulfurization reaction. Reaction products such as $\mathrm{H}_{2} \mathrm{O}$ could cause delamination of the $\mathrm{MoS}_{2}$ films at the interface due to byproduct accumulation. Reducing substrates in combination with permeable thin layers could decrease film delamination.

After full sulfurization, the films recrystallize and their orientation is found to depend on the surface roughness of the underlying substrate. Hence, flat substrates such as native oxides or thermal dry oxides result in horizontal basal plane arrangement, whereas rougher substrates such as very thick wet oxide induce rather random basal plane orientation.

The high temperature process resulted in the formation of grains of a few $100 \mathrm{~nm}^{2}$ and showed evolving PL on the ultra-thin films. This work shows that the sulfurization chemistry and process temperature need to be carefully adjusted for the material to be sulfurized and that the interface roughness plays an important role for the assembly of the basal planes. Further work, in view of a successful very large scale integration, will have to concentrate on the increase of the lateral grain size to minimize defects and improve electrical properties.

\section{Acknowledgements}

The authors appreciate the funding by the Agency for Innovation by Science and Technology (IWT).

\section{References}

1 B. Radisavljevic, A. Radenovic, J. Brivio, V. Giacometti and A. Kis, Nat. Nanotechnol., 2011, 6, 147-150.

2 K. Alam and R. K. Lake, IEEE Trans. Electron Devices, 2012, 59, 3250-3254.

3 R. Addou, S. McDonnell, D. Barrera, Z. Guo, A. Azcatl, J. Wang, H. Zhu, C. L. Hinkle, M. Quevedo-Lopez, H. N. Alshareef, L. Colombo, J. W. P. Hsu and R. M. Wallace, ACS Nano, 2015, 9, 9124-9133.

4 R. Addou, L. Colombo and R. M. Wallace, ACS Appl. Mater. Interfaces, 2015, 7, 11921-11929.

5 S. McDonnell, R. Addou, C. Buie, R. M. Wallace and C. L. Hinkle, ACS Nano, 2014, 8, 2880-2888.

6 D. Sharma, M. Amani, A. Motayed, P. B. Shah, A. G. Birdwell, S. Najmaei, P. M. Ajayan, J. Lou, M. Dubey, Q. Li and A. V Davydov, Nanotechnology, 2014, 25, 155702.

7 W. Zhang, J.-K. Huang, C.-H. Chen, Y.-H. Chang, Y.-J. Cheng and L.-J. Li, Adv. Mater., 2013, 25, 3456-3461.

8 K. K. H. Smithe, C. D. English, S. V. Suryavanshi and E. Pop, in 2015 73rd Annual Device Research Conference (DRC), IEEE, 2015, vol. 3087, pp. 239-240.

9 Y. Zhan, Z. Liu, S. Najmaei, P. M. Ajayan and J. Lou, Small, 2012, 8, 966-971.

10 G. Plechinger, J. Mann, E. Preciado, D. Barroso, A. Nguyen, J. Eroms, C. Schüller, L. Bartels and T. Korn, Semicond. Sci. Technol., 2014, 29, 064008.

11 D. N. Nath, M. Lu, H. L. Chong, E. Lee, A. Arehart, W. Yiying and S. Rajan, Electron transport in large-area epitaxial MoS2, in Device Research Conference (DRC), 2014 72nd Annual, pp. 89-90, 22-25 June 2014, DOI: 10.1109/DRC. 2014.6872311.

12 H. Schmidt, S. Wang, L. Chu, M. Toh, R. Kumar, W. Zhao, A. H. Castro Neto, J. Martin, S. Adam, B. Özyilmaz and G. Eda, Nano Lett., 2014, 14, 1909-1913.

13 S. Ghosh, S. Najmaei, S. Kar, R. Vajtai, J. Lou, N. R. Pradhan, L. Balicas, P. M. Ajayan and S. Talapatra, Phys. Rev. B: Condens. Matter Mater. Phys., 2014, 89, 125422. 
14 Y. Lee, J. Lee, H. Bark, I.-K. Oh, G. H. Ryu, Z. Lee, H. Kim, J. H. Cho, J.-H. Ahn and C. Lee, Nanoscale, 2014, 6, 2821-2826.

15 J. M. Wilson, Surf. Sci., 1975, 53, 330-340.

16 Y. Shi, Y. Wan, R. Liu, B. Tu and D. Zhao, J. Am. Chem. Soc., 2007, 129, 9522-9531.

17 L. P. Hansen, E. Johnson, M. Brorson and S. Helveg, J. Phys. Chem. C, 2014, 118, 22768-22773.

18 J. A. Miwa, M. Dendzik, S. S. Grønborg, M. Bianchi, J. V Lauritsen, P. Hofmann and S. Ulstrup, ACS Nano, 2015, 9, 6502-6510.

19 D.-W. Lee, J. Lee, I. Y. Sohn, B.-Y. Kim, Y. M. Son, H. Bark, J. Jung, M. Choi, T. H. Kim, C. Lee and N.-E. Lee, Nano Res., 2015, 8, 2340-2350.

20 I. Song, C. Park, M. Hong, J. Baik, H. J. Shin and H. C. Choi, Angew. Chem., Int. Ed., 2014, 53, 1266-1269.

21 H. G. Füchtbauer, A. K. Tuxen, Z. Li, H. Topsøe, J. V. Lauritsen and F. Besenbacher, Top. Catal., 2014, 57, 207-214.

22 Y.-C. Lin, R. K. Ghosh, R. Addou, N. Lu, S. M. Eichfeld, H. Zhu, M.-Y. Li, X. Peng, M. J. Kim, L.-J. Li, R. M. Wallace, S. Datta and J. A. Robinson, Nat. Commun., 2015, 6, 7311.

23 R. Yue, A. T. Barton, H. Zhu, A. Azcatl, L. F. Pena, J. Wang, X. Peng, N. Lu, L. Cheng, R. Addou, S. Mcdonnell, L. Colombo, J. W. P. Hsu, J. Kim, M. J. Kim, R. M. Wallace and C. L. Hinkle, ACS Nano, 2015, 9, 474-480.

24 B. Holländer, H. Heer, M. Wagener, H. Halling and S. Mantl, Nucl. Instrum. Methods Phys. Res., Sect. B, 2000, 161-163, 227-230.

25 N. H. Turner and A. M. Single, Surf. Interface Anal., 1990, 15, 215-222.

26 J.-G. Choi and L. T. Thompson, Appl. Surf. Sci., 1996, 93, 143-149.

27 M. a Albiter, R. Huirache-Acuña, F. Paraguay-Delgado, J. L. Rico and G. Alonso-Nuñez, Nanotechnology, 2006, 17, 3473-3481.

28 B. Schönfeld, J. J. Huang and S. C. Moss, Acta Crystallogr., Sect. B: Struct. Sci., 1983, 39, 404-407.

29 A. V. Chichagov, Kristallografiya, 1990, 35, 610-616.

30 A. Gurarslan, Y. Yu, L. Su, Y. Yu, F. Suarez, S. Yao, Y. Zhu, M. Ozturk, Y. Zhang and L. Cao, ACS Nano, 2014, 8, 11522-11528.

31 N. Scheuschner, O. Ochedowski, A.-M. Kaulitz, R. Gillen, M. Schleberger and J. Maultzsch, Phys. Rev. B: Condens. Matter Mater. Phys., 2014, 89, 125406.
32 Q. Ji, Y. Y. Zhang, T. Gao, D. Ma, M. Liu, Y. Chen, X. Qiao, P.-H. Tan, M. Kan, J. Feng, Q. Sun and Z. Liu, Nano Lett., 2013, 13, 1-15.

33 A. Splendiani, L. Sun, Y. Zhang, T. Li, J. Kim, C.-Y. Chim, G. Galli and F. Wang, Nano Lett., 2010, 10, 1271-1275.

34 K. F. Mak, K. He, C. Lee, G. H. Lee, J. Hone, T. F. Heinz and J. Shan, Nat. Mater., 2013, 12, 207-211.

35 K.-K. Liu, W. Zhang, Y. Lee, Y.-C. Lin, M.-T. Chang, C.-Y. Su, C.-S. Chang, H. Li, Y. Shi, H. Zhang, C.-S. Lai and L.-J. Li, Nano Lett., 2012, 12, 1538-1544.

36 X. Lee, X. Li, X. Zang, M. Zhu, Y. He, K. Wang, D. Xie and H. Zhu, Nanoscale, 2015, 8398-8404.

37 A. P. S. Gaur, S. Sahoo, M. Ahmadi, S. P. Dash, M. J. F. Guinel and R. S. Katiyar, Nano Lett., 2014, 14, 4314-4321.

38 T. Bakos, S. N. Rashkeev and S. T. Pantelides, Phys. Rev. Lett., 2002, 88, 055508.

39 S. Kostinski, R. Pandey, S. Gowtham, U. Pernisz and A. Kostinski, IEEE Electron Device Lett., 2012, 33, 863-865.

40 D. Kong, H. Wang, J. J. Cha, M. Pasta, K. J. Koski, J. Yao and Y. Cui, Nano Lett., 2013, 13, 1341-1347.

41 J. Lee, P. Dak, Y. Lee, H. Park, W. Choi, M. A. Alam and S. Kim, Sci. Rep., 2014, 4, 7352.

42 D. Sercombe, S. Schwarz, O. Del Pozo-Zamudio, F. Liu, B. J. Robinson, E. A. Chekhovich, I. I. Tartakovskii, O. Kolosov and A. I. Tartakovskii, Sci. Rep., 2013, 3, 3489.

43 N. Choudhary, J. Park, J. Y. Hwang and W. Choi, ACS Appl. Mater. Interfaces, 2014, 6, 21215-21222.

44 M. Maeda, K. Nakamura and T. Ohkubo, J. Mater. Sci., 1989, 24, 2120-2126.

45 P. O. Hahn, J. Appl. Phys., 1981, 52, 4122.

46 J. Zhang, H. Yu, W. Chen, X. Tian, D. Liu, M. Cheng, G. Xie, W. Yang, R. Yang, X. Bai, D. Shi and G. Zhang, ACS Nano, 2014, 8, 6024-6030.

47 Z. Jin, S. Shin, D. H. Kwon, S.-J. Han and Y.-S. Min, Nanoscale, 2014, 6, 14453-14458.

48 E. Minni and F. Werfel, Surf. Interface Anal., 1988, 12, 385-390.

49 R. Kappera, D. Voiry, S. E. Yalcin, B. Branch, G. Gupta, A. D. Mohite and M. Chhowalla, Nat. Mater., 2014, 13, 1128-1134.

50 Y. Lu, X. Yao, J. Yin, G. Peng, P. Cui and X. Xu, RSC Adv., 2015, 5, 7938-7943.

51 L. Jiang, S. Zhang, S. A. Kulinich, X. Song, J. Zhu, X. Wang and H. Zeng, Mater. Res. Lett., 2015, 3, 177-183. 